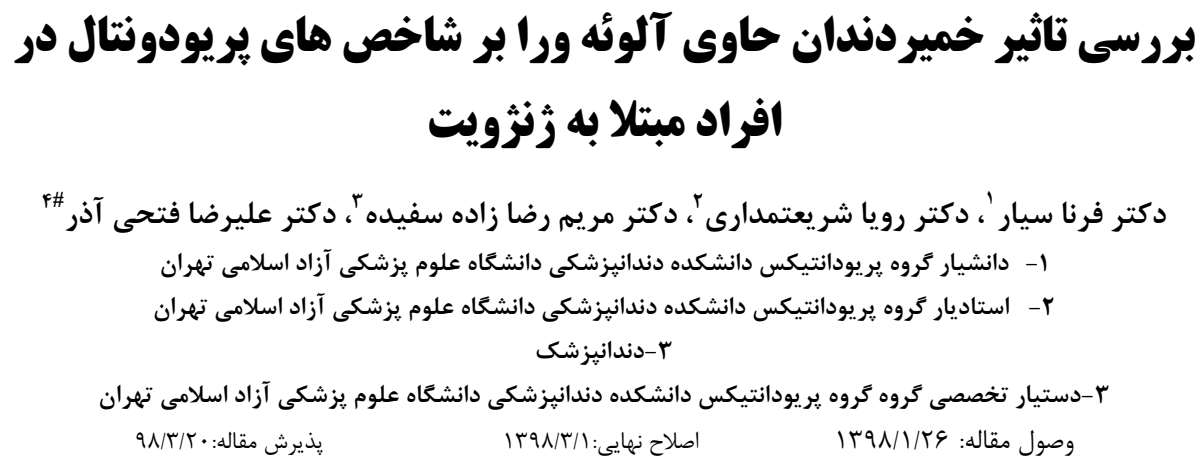

\title{
Evaluation of the efficacy of Aloevera toothpaste on Periodontal index in patients with gingivitis
}

\author{
Ferena Sayar ${ }^{1}$, Roya Shariatmadari ${ }^{2}$, Maryam Rezazadeh Sefideh $^{3}$, Alireza Fathiazar ${ }^{4 \#}$ \\ ${ }^{1}$ Associate Prof, Periodontic Dept, Faculty of Dentistry, Tehran Medical Sciences, Islamic Azad University, Tehran, Iran \\ ${ }^{1}$ Assistant Prof, Periodontic Dept, Faculty of Dentistry, Tehran Medical Sciences, Islamic Azad University, Tehran, Iran \\ ${ }^{3}$ Dentist \\ ${ }^{4}$ Post Graduate Student, Periodontic Dept, Faculty of Dentistry, Tehran Medical Sciences, Islamic Azad University, Tehran, Iran
}

Received: 16 April２019; Accepted: 11 June 2019

\section{Abstract}

Background and AIM: Plaque-induced gingivitis is a common gingival disease. There are some limitations in mechanical methods to promote plaque control which is why chemical methods have been introduced. Chemical toothpastes have side effects like hypersensitivity and staining, so the tendency is growing towards herbal toothpastes. Our aim in this study was to evaluate the effectiveness of Aloevera tooth paste on gingivitis. Materials and methods: This was a Single blind cross over clinical trial study which was conducted on 20 dental students ( 10 male, 10 female with the average of $24.5 \pm 4$ years) who had gingivitis. Then, they were divided into 2 groups: The first group used the Aloevera toothpaste for 30 days and PI and GI was recorded. They had been washed out for 2 weeks and after that they used the Fluoride toothpaste for another 30 days. Again, PI and GI was recorded. In the second group the toothpastes were used in an opposite order. The Wilcoxon test was used to evaluate statistical analysis.the level of significance was set as 0.06 .

Results:There was no significant difference in periodontal records between toothpastes after 30 days of administration. After 30 days, PI changed from $2.14 \pm 1.3$ to $1.84 \pm 1.02(\mathrm{P}<0.098)$ and GI changed from $0.74 \pm 0.62$ to $0.25 \pm 0.46(\mathrm{P}<0.068)$ and the $\mathrm{P}$-value between the toothpastes was $\mathrm{P}<0.07$ for $\mathrm{PI}$ and $\mathrm{P}<0.308$ for GI.

Conclusion: Aloevera toothpaste may have the same effect on PI and GI as the Fluoride tooth paste, So it can be concluded the this toothpaste could be used instead of conventional chemical toothpastes.

Keywords: Aloe vera, Toothpaste,dental palque index, Periodontal index,Gingivitis

*Corresponding Author: alireza fathiazar@yahoo.com

J Res Dent Sci. 2019;16 (2):72-77. 
سابقه و هدف: زنزويت وابسته به پِلاك يكى از رايج ترين بيمارى هاى دهان است. محدوديت هايى در روش هاى مكانيكى، كه به عنوان رايج ترين روش كنترل يُلاك ميكروبى است، وجود دارد. با توجه به عوارض خميردندان هاى شيميايى مانند حساسيت و ايجاد

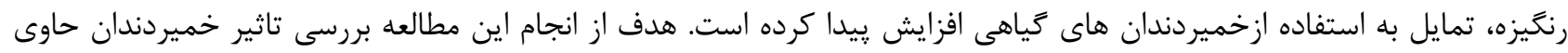

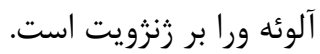

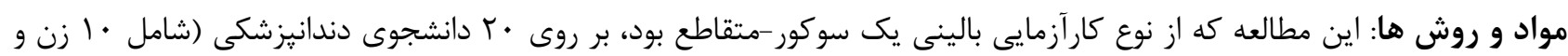

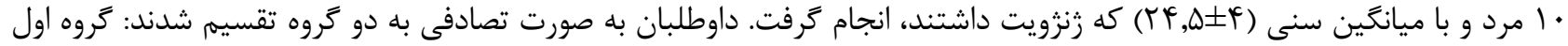

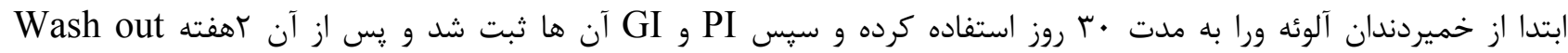

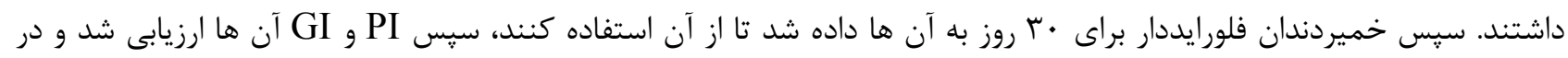

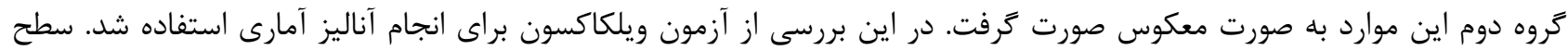

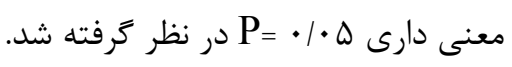

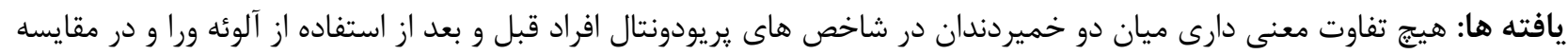

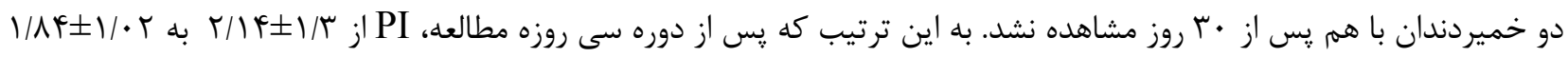

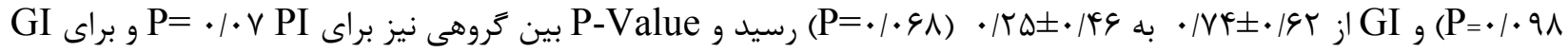

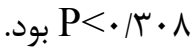

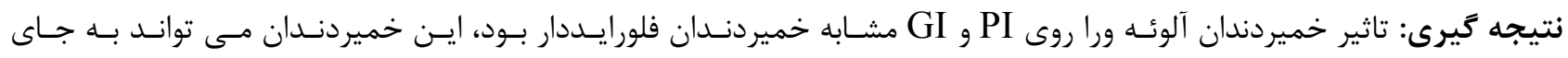
خميردندان هاى شيميايى تجويز تردد.

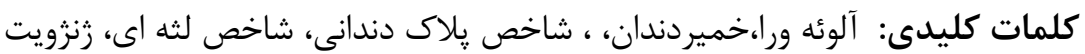

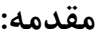

تا در حذف يا كاهش عوامل موضعى ايجاد كننده بيمارى هاى يريودونتال به همراه روش هاى مكانيكال موثرتر عمل كنند. امروزه تمايل به استفاده از خميردندان هاى گياهى با لـ توجه به عوارض كم تر و ايجاد حساسيت محدود افزايش ريدا (4) كرده است IVD • سابقه استفاده از زياه آلوئه ورا براى مصارف يزشكى به قبل از ميلاد مى رسد. آلوئه ورا گياهى است كه مواد حاصل از برگ آن داراى خاصيت ضد ميكروبى، ضد التهابى مى باشد. تركيبات موجود در آلوئه ورا از جمله Aloin و-Aloe داراى فعاليت ضد باكتريال و ضد ويروسى هستند كه مى تواند اثر ضد التهابى اين ماده را نشان دهد. (ه) آلوئه ورا يك زياه دارويى است كه متعلق به خانواده liliaceae و شبيه كاكتوس مى باشد كه در مناطق گرم و خشك مى رويد و براى مصارف يزشكى مانند مشكلات گوارشى، در مان زخم
يكى از شايع ترين بيمارى هاى يريودونتال زنزويت مى باشد. اين بيمارى يك بيمارى التهابى مزمن است كه محدود به بافت نرم لثه مى شود و معمولا در پاسخ به پيلاك باكتريايى

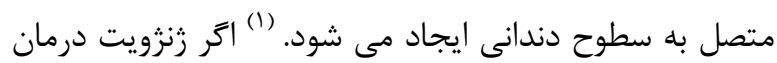
نشود، مى تواند به يريودنتيت تبديل شده و مشكلات جدى تر را در محيط دهان( تحليل استخوان و از دست دادن دندان ها) و خارج از دهان ( بيمارى هاى قلبى،تنفى، افزايش احتمال يره اكلاميسى در زنان باردارو...) ايجاد كند. (r.r) در حال حاضر براى حذف يلاى باكتريال از روش هاى بـ برى مختلف رعايت بهداشت دهان شامل روش هاى مكانيكى و شيميايى استفاده مى شود. روش هاى مكانيكى مى تواند به طور موثر ميزان يلاك باكتريال را كاهش دهد ولى از آنجايى كه اكثر مردم نمى توانند به صورت مناسب از روش هاى مكانيكى استفاده كنند، لذا روش هاى شيميايى معرفى شده

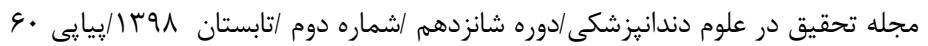


Pر ابتداى مطالعه شاخص هاى يريودونتال Pl(Plaque

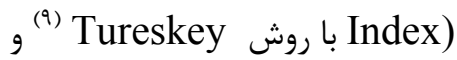
Gi(Gingival Index) كيرى و ثبت شد) •(1). به بيماران روش مسواك زدن Bass

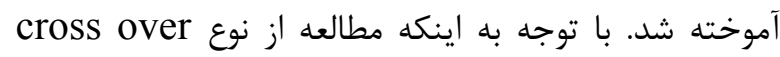
بود، افراد با روش تصادفى در دو نوبت · ب روزه از دو نوع

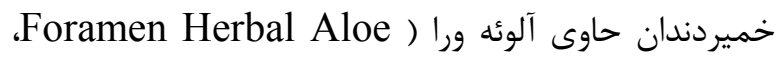
ساخت كشور اسيانيا با غلظت ه, •• آلوئه ورا) و خميردندان حاوى فلورايد(Signal، ساخت كشور هند) استفاده كردند. يك گروه ده نفره ابتدا خميردندان حاوى آلوئه ورا به مدت

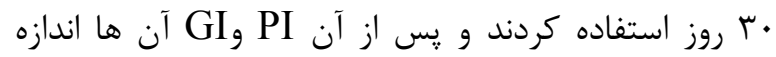

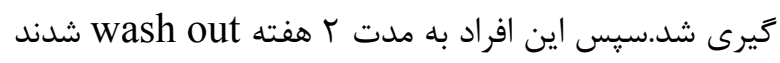
كه در اين دوره از خميردندان هاى معمولشان استفاده كردند.

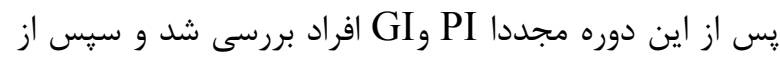

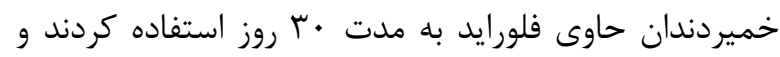
مجددا GI PI آن ها اندازه گيرى شد .در تروه بعدى شامل ده داوطلب ديكر، ابتدا از خميردندان حاوى فلورايد و سيس از خميردندان حاوى آلوئه ورا استفاده شد. براى هر دو خميردندان وزن تيوب قبل از استفاده (روز صفر) و پِ از

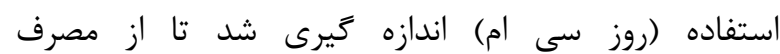
خميردندان ها توسط بيمار اطمينان حاصل شود.(r)

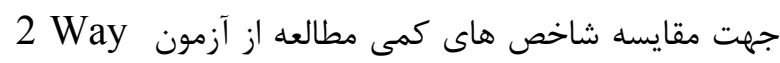
Repeated Meassure ANOVA

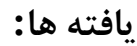
در اين مطالعه به منظور بررسى اثر خمير دندان حاوى آلوئه

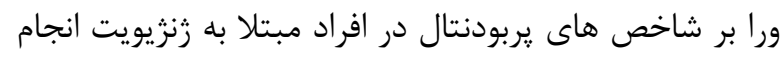

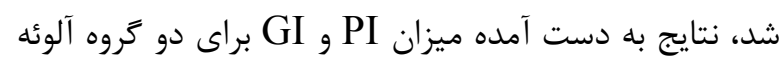
وراو فلورايد در جداول ا و r نشان داده شده است. همانطور

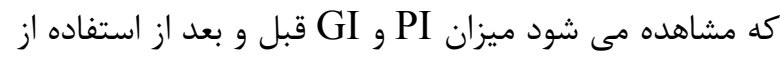

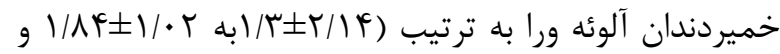

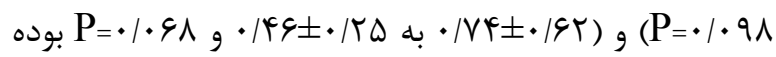
است. همجنين ميان آلوئه ورا و فلورايد نيز تفاوت معنى دارى به
ها، عفونت هاى يوستى، سينوزيت و... استفاده مى شود. (\$) در برخى مطالعات تاثير مثبت آلوئه ورا بر كاهش التهاب لثه و ترميم سريعتر زخم هاى لثه اي اشاره شده است. (v) آلوئه ورا در فرم هاى مختلفى از جمله خميردندان، دهانشويه

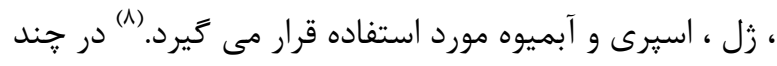
دهه اخير ، مطالعات مختلفى انجام شده كه به بررسى تاثير

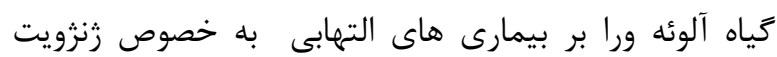

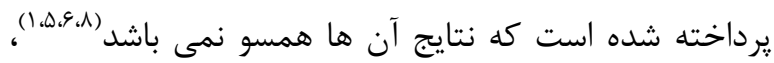
لذا هدف از انجام اين تحقيق ، بررسى تاثير خميردندان حاوى گياه آلوئه ورا بر شاخص هاى يريودونتالى افراد مبتلا

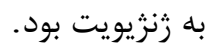
مواد و روش ها:

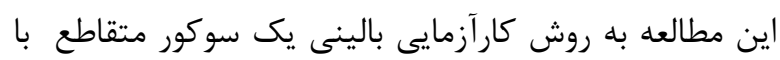

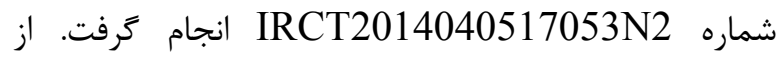
دانشجويان دندانيزشكى (•ا مرد و •ا زن) داشكاه آزاد

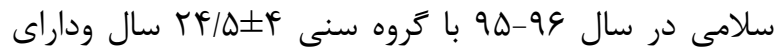
حداقل •r د دندان در دهان كه زنزويت داشتند با اخذ رضايتمندى كتبى وارد مطالعه شدند.

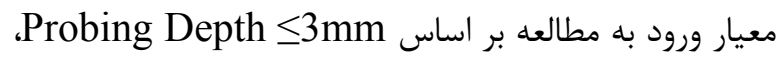
Bleeding , Clinical Attachment Level $\leq 1 \mathrm{~mm}$ Plaque در بيش از • بَ٪ مناطق مثبت بود و on Probing

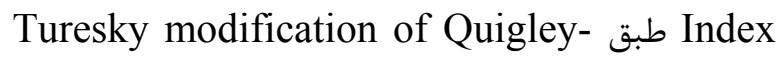
r Gingival Index بيشتر از Y Hein plaque index و بالاتر بود ، ، كه در اين صورت تشخيص زنزويت داده شد. (9) بن بيمارانى كه هرگونه مصرف آنتى بيوتيك و داروهاى ضدالتهابى در r ماه حذشته ، باردارى، شيردهى و بيمارى هاى سيستميك موثر بر لثه (بيمارى هاى خونى، سابقه آلرزى) داشتند از مطالعه حذف شدند. هم خنين افرادى كه

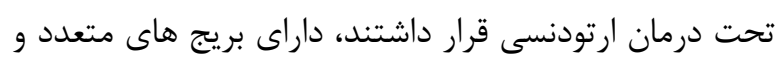

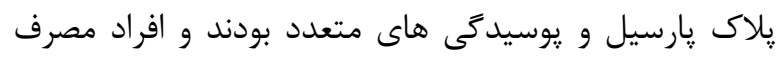
كننده دخانيات از مطالعه حذف شدند. 
به دنبال استفاده موضعى از اين گياه افزايش مى يابد و ترميم

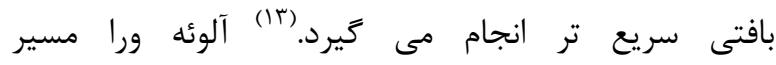

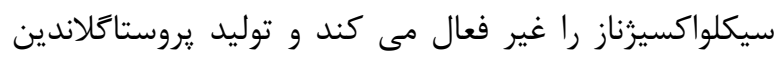

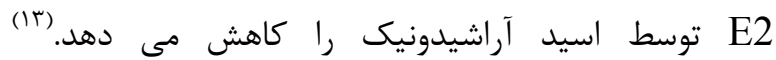

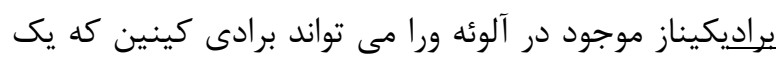
-pp-value P-Value

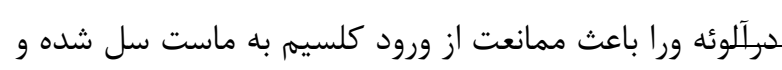

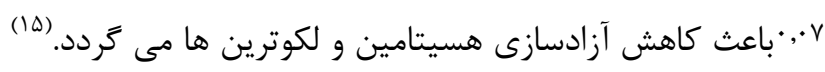
همجنين آلوئه ورا باعث كاهش توليد IL-1 و و شود و از اين طريق باعث كاهش التهاب مى كردد.

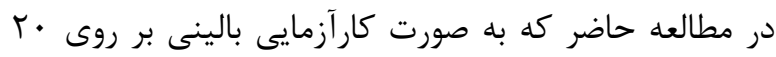
فرد مبتلا به زنززويت به منظور بررسى تاثير خميردندان حاوى

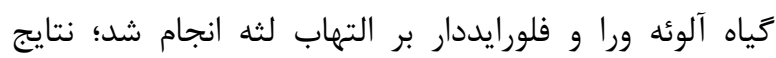

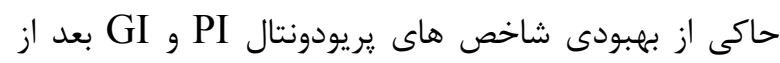

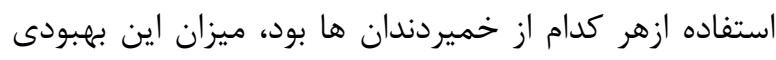

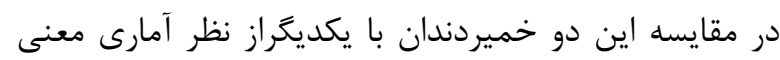

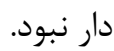
در קند دهه اخير ، مطالعات مختلفى انجام شده كه به بررسى تاثير كياه آلوئه ورا بر بيمارى هاى التهابى به به خضوص زنزويت يرداخته شده است كه نتايج آن ها همسو

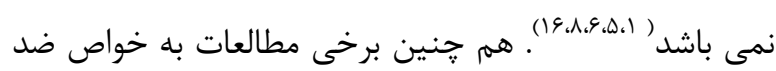

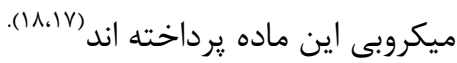
دكتر فانى و همكاران به بررسى اثر مهارى زل كياه آلوئه ورا

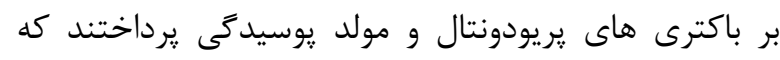
نتايج به اين ترتيب بود كه غلظت مناسب آلوئه ورا اثر آنتى بردي سيتيك بر بيمارى هاى يريودونتال دارد و اكر از غلظت

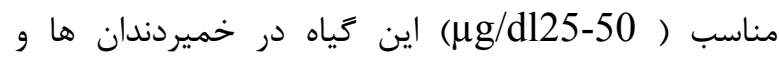
دهانشويه ها استفاده شود ، مى توان از آن در بيشكيرى از بيمارى هاى بريودونتال استفاده كرد. در حيطه دندانيزشكى آلوئه ورا در فرم هاى مختلفى از جماده درديه خميردندان، دهانشويه ، زل ، اسيرى و آبميوه مورد استفاده

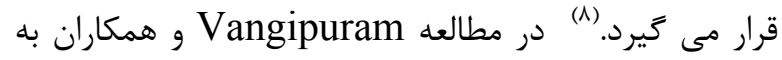
بررسى دهانشويه آلوئه ورا با كلرهًَيدين بر مريه روى سلامت

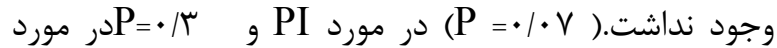

(GI

جدول ا- ميانكَين ميزان PI در زمان هاى صفر و يك ماه يس از

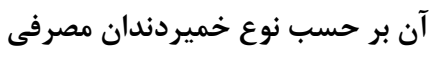

\begin{tabular}{|c|c|c|c|}
\hline .119 & $1 / 9 F \pm \cdot / \Delta r$ & $r / r \mid \pm 1 / \cdot r$ & فلورايد \\
\hline .1 .91 & $1 / \Lambda f \pm 1 / \cdot r$ & $r / l f \pm \| / r$ & آلوئه ورا \\
\hline
\end{tabular}

جدول r- ميانكين ميزان GI در زمان هاى صفر و يك ماه يس از آن بر حسب نوع خميردندان مصرفى معلى

\begin{tabular}{|c|c|c|c|c|}
\hline P-value & P- Value & $\begin{array}{c}\text { بعد از يكى ماه } \\
\text { (mean } \pm \text { SD) }\end{array}$ & $\begin{array}{c}\text { روز صفر } \\
(\text { mean } \pm \text { SD) }\end{array}$ & \\
\hline \multirow[t]{2}{*}{$\cdot / r$} & $\cdot / 1 \mathrm{~V}$ & ( $/ \pi \mid \pm \cdot / 4 \Lambda$ & $\cdot \mid q \nabla \pm \cdot / q \mu$ & فلورايد \\
\hline & .1 .91 & $\cdot / r \Delta \pm \cdot / 49$ & $\cdot / 9 Y \pm \cdot / V Y$ & آلوئه ورا \\
\hline
\end{tabular}

در مطالعه حاضر كه به صورت كارآزمايى بالينى بر روى فرد مبتلا به زنزويت به منظور بررسى تاثير خميردندان حاوى كياه آلوئه ورا و فلورايددار بر التهاب لثه انجام شد؛ نتهايج

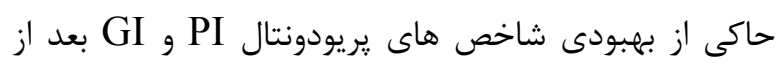

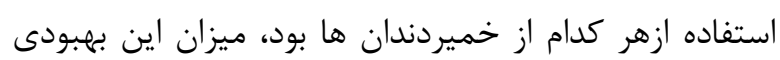

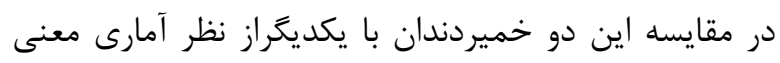

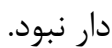
آلوئه ورا يك كياه قديمى است كه داراى سابقه طولاتى براى مصارف يزشكى مى باشد. آلوئه ورا كياهى است كه عمدتا در مناطق با آب و هواى خشك مى رويد و بيشتر در آفريقا و

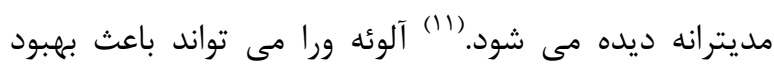
عملكرد سيسته ايمنى و افزايش سرعت ترميم بافتى تردد

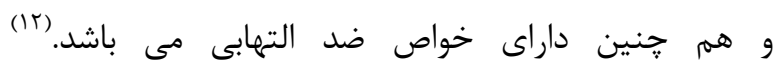

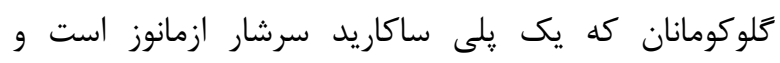

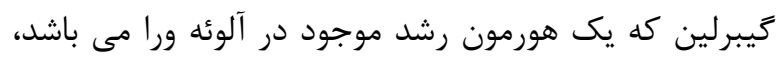

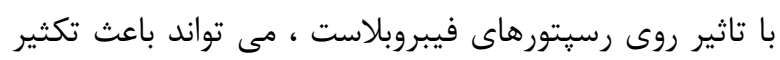

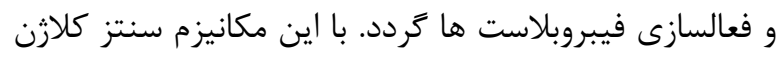

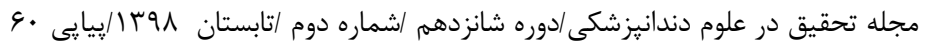


تاثير آلوئه ورا در كاهش التهاب كم بود. (r) در اين مطالعه

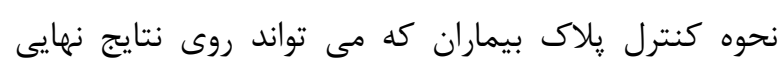

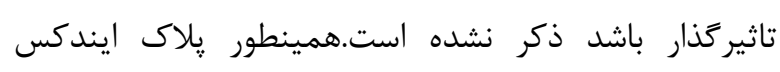

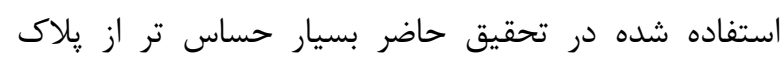

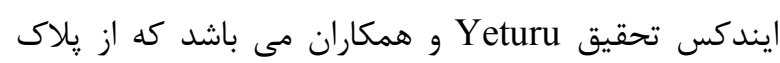
ايندكس O'leary استفاده كرده بودند. مطالعه اي توسط Geetha Bhat و همكاران انجام گرفت

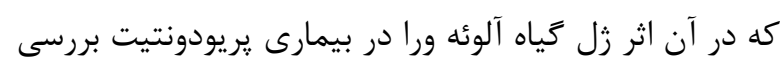

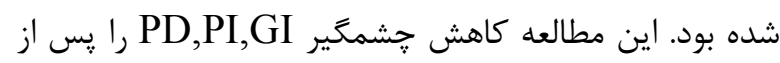

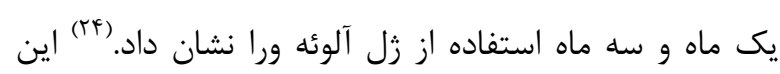

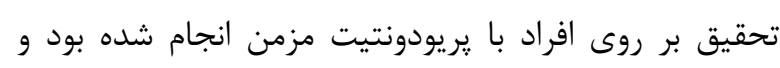

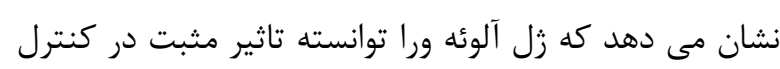

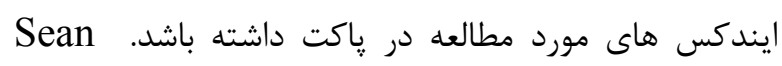

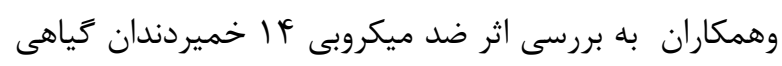

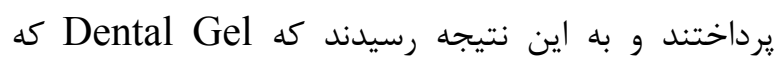

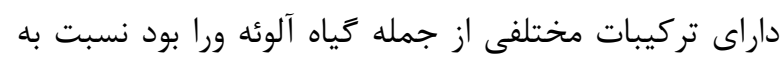

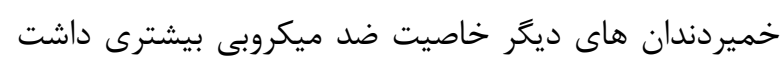

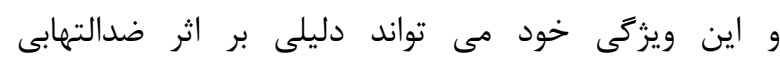

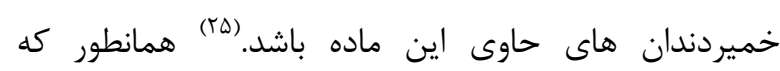
مشاهده مى شود مطالعات زيادى در زمينه استفاده از آلوئه

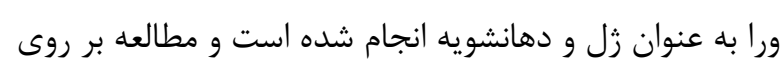

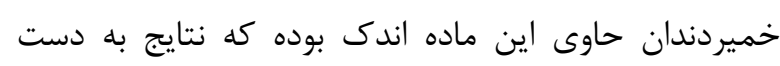

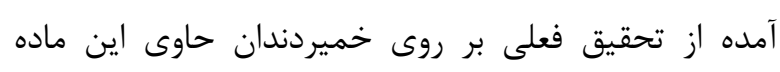

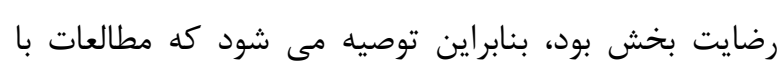
follow up بيمارى هاى پيشرفته يريودونتال انجام گيرد.

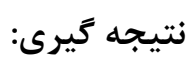

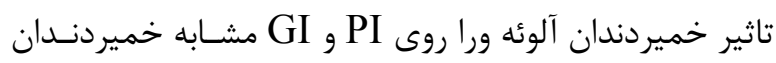

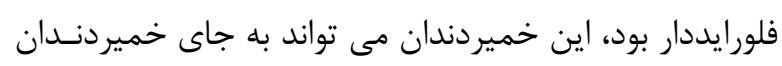
هاى شيميايى تجويز گردد.
يريودونتال يرداختند. بيماران بر اساس كاهش ميزان Gingival Index و مورد ارزيابى قرار كرفتند. نتايج نشان داد كه هر دو نوع دهانشويه باعث بهبود

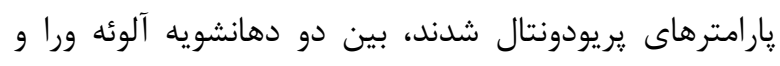
كلرهكزيدين تفاوت آمارى معنى دارى مشاهده نشد كه نشان

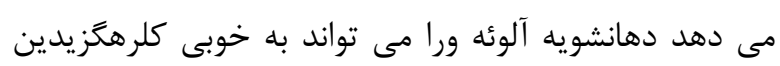

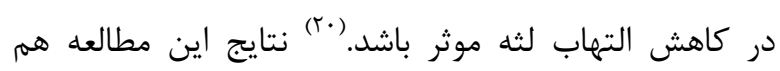
راستا با نتايج به دست آمده از تحقيق حاضر مى باشد.

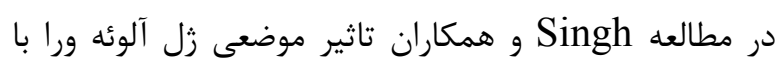

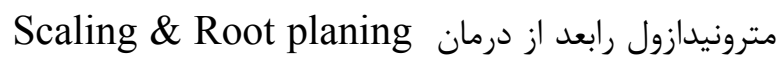

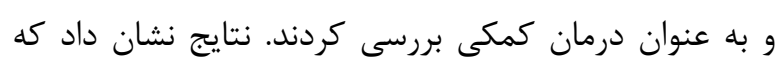

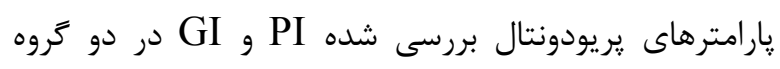
نسبت به گروه SRP تنها بهتر بود ولى بين دو گروه آلوئه ورا با مترونيدازول تفاوت معنى دارى وجود نداشت. نتايج مطالعه

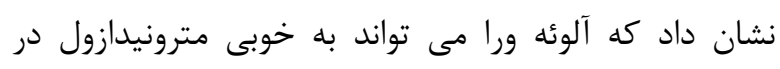
كاهش التهاب موثر باشد و در عين حال عوارض جانبى آن آن را

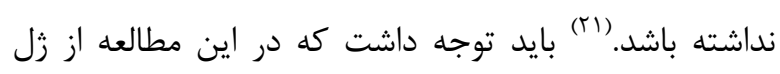
موضعى براى بيماران Chronic Periodontitis استفاده

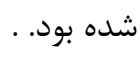
Sahgal

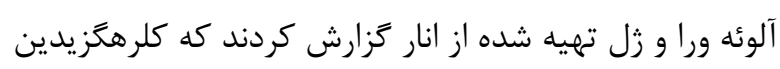

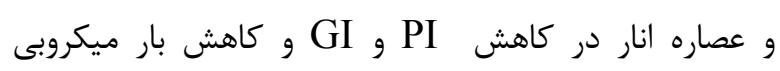
موثرتر عمل كردند و آلوئه ورا تاثير ناجيزى در كاهش وارث

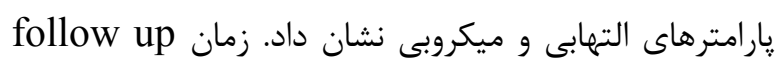

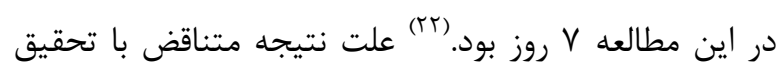
فعلى ممكن است به علت زمان كم ييخيرى در اين تحقيق باشد.

و و همكارانش ميزان كاهش التهاب لثه بعد از

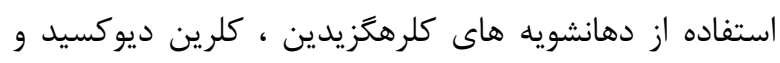
آلوئه ورا را بررسى كردند. نتايج مطالعه نشان داد كه ميزان

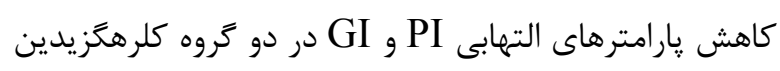

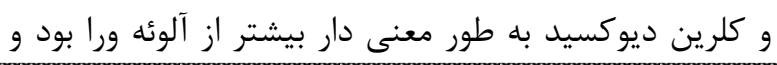




\section{References:}

1. Samuels N1, Grbic JT, Saffer AJ, Wexler ID, Williams RC. Effect of a herbal mouth rinse in preventing periodontal inflammation in an experimental gingivitis model: a pilot study. Compend Contin Educ Dent 2012; 33(3):204-8.

2. Jayashankar S, Panagoda GJ, Amaratunga EA, Perera K, Rajapakse PS. A randomized double-blind placebocontrolled study on the effects of a herbal toothpaste on gingival bleeding, oral hygiene and microbial variables. Ceylon Med J 2011;56(1):5-9.

3. Scannapieco Frank A, Bush Renee B, Paju Susann. Association between periodontal disease and risk for atherosclerosis, cardiovascular disease and stroke. A systematic Review. Ann Periodontol 2003; 8(1):38-53

4. C. Ashwini Somu, S. Ravindra, Soumya Ajith, Mohammed Gulzar Ahamed. Efficacy of a herbal exact gel in the treatment of gingivitis. J Ayurveda Inter Med 2012;3(2):85-90.

5. Pradeep A, Agarwal E, Niak S. Clinical and microbiologic effect of commercially available dentifrice containing aloe vera : A randomized clinical controlled trial. J Periodontol 2012; 83(6):797-804.

6. Ndhlala AR, Amoo SO, Stafford GI, Finnie JF, Van Staden J. Antimicrobial, anti-inflammatory and mutagenic investigation of the South African tree aloe (aloe barberare). J Ethnopharmacol 2009; 124(3):404-8.

7. Mangaiyarkarasi SP, Manigandan $\mathrm{T}$, Elumalai $\mathrm{M}$, Cholan PK, Kaur RP. Benefits of Aloe vera in dentistry. J Pharm Bioallied Sci 2015;7(1):255-9.

8. George D, Bhat SS, Antony B, Comparative evaluation of antimicrobial efficacy of Aloe vera toothgel and two popular commercial toothpastes: an invitro study. Gen Dent 2009;57(3): 238-41

9. Sean S, Lee, Wu Zhang, Yiming LI. The antimicrobial potential of 14 natural herbal dentifrices. J Am Dent Assoc 2004; 135(8):1133-41.

10. Loe $H$. The gingival index, the plaque index and the retention index systems.J Periodontol 1967; 36(6):610-6.

11. Subramaniam T, Subramaniam A, Chowdhery A, Das S, Gill M. Versatility of Aloe Vera in Dentistry-A review. J Dent Med Sci 2015; 1(13):98-102.

12- Rajeswari R et al, Aloe vera: The Miracle Plant Its Medicinal and Traditional Uses in India, Journal of Pharmacognosy and Phytochemistry 2012; 1(4) :118-24

13. Renu Tanwar, Jyoti Gupta,, Sheikh Asif,, Rajneesh Panwar, Rashmi Heralgi. Aloe Vera and its uses in Dentistry, Indian J Dent Adv 2011; 3(4): 656-8.
14. Sajjad A, Samia Subhani Sajjad. Aloe vera: An Ancient Herb for Modern Dentistry-A Literature Review. J Dent Surg 2014;1-6.

15. Manoj Meena, Nigel R. Figueiredo, Khyati Trivedi. Aloe vera - An Update for Dentistry, J Dentofacial Sci $2013 ; 2(4): 1-4$.

16. Kamath NP, Tandon S, Nayak R, Naidu S, Anand PS, Kamath YS. The effect of aloe vera and tea tree oil mouthwashes on the oral health of school children. Eur Arch Paediatr Den 2019;6(20):1-6.

17. Shakerian M, Khorasani MM, Doostaki S. In Vitro Effect of Hydroalcoholic Extract of Aloe Vera and 0.2\% Chlorhexidine Mouthwash on Streptococcus Sanguinis, Streptococcus Salivarius and Streptococcus Mutans. Journal of Dental School 2018;36(1):18-22.

18. Korkmaz FM, Ozel MB, Tuzuner T, Korkmaz B, Yayli N. Antimicrobial activity and volatile constituent analysis of three commercial herbal toothpastes containing Aloe vera L. and Fragaria vesca L. extracts. Niger J Clin Pract 2019;22(5):557-18.

19. Fani M, Kohanteb J. Inhibitory activity of aloe vera on some clinically isolated cariogenic and periodontopathic bacteria. J Oral Sci 2012;5(4):15-21.

20. Vangipuram S, Jha A, Bhashyam. Comparative efficacy of aloe vera mouthwash and chlorhexidine on periodontal health: A randomized controlled trial. J Clin Exp Dent 2016;8(4):442-7.

21. Harinder Paul Singh1, Muzammil2, G Sathish3, K Nagendra Babu4, KS Vinod5, Hari Prasad Rao. Comparative study to evaluate the effectiveness of aloe vera and metronidazole in adjunct to scaling and root planning in periodontitis patients. J Int Oral Health 2016;8(3):374-7.

22. Saghal A, Chaturvedi SS, Bagde H, Agrawal P, Suruna R, Limaye M. A randomized controlled trial to evaluate efficacy of anti-bacterial and anti-inflammatory effect of Aloe vera, Pomegranate and Chlorhexidine gel against periopathogens. J Int Oral Health 2015; 7(11):1-4. 23. Yeturu SK, Acharya S, Urala AS, Pentapati KC. Effect of Aloe vera, chlorine dioxide and chlorhexidine mouth rinses on plaque and gingivitis: A randomized controlled trial. J Oral Biol Craniofac Res 2016;6(1):54-8. 24. Geetha Bhat, Praveen K, Vidya D. Aloe vera : Natures soothing healer to periodontitis disease. J Indian Soc Periodontol 2011;15(3):205-9.

25. Sean S, LEE, Wu Zhang, Yiming LI. The antimicrobial potential of 14 natural herbal dentifrices. J Am Dent Assoc 2004 ;135(8):1133-41

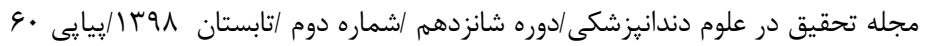

